\title{
Torsion of the testis: why is the prognosis so poor?
}

\author{
S BENNETT, M S NICHOLSON, T M LITTLE
}

\begin{abstract}
The cases of 83 boys who were admitted to hospital with acute testicular pain or swelling were studied. Twenty seven had torsion of the testis, and $15(55 \%)$ of these lost a testis. The main reason for the poor results was delay by the patient or his parents in seeking medical attention.
\end{abstract}

\section{Introduction}

It has long been taught that all acutely painful testes need urgent exploratory surgery if torsion of the testis is not to be missed. Despite this many testes are lost, a tragedy that has traditionally been attributed to delays in diagnosis by general practitioners and casualty officers. The results of our survey show that this view is wrong and that the main reason for the poor results is delay by the patient or his parents in seeking medical attention.

\section{Patients and results}

Eighty three boys aged from 3 months to 16 years with acute testicular pain or swelling were admitted to the Medway Hospital; Gillingham, between 1979 and 1985; the hospital has a catchment population of 330000 .

Details of diagnoses and delays in seeking treatment by patients with acute testicular pain

\begin{tabular}{lrrc}
\hline \multicolumn{1}{c}{ Diagnosis } & & \multicolumn{2}{c}{ Time (hours) } \\
\cline { 3 - 4 } & No & Mean & Range \\
\hline Torsion of hydatid of Morgagni & 37 & 42 & $3-72$ \\
Torsion of testis & 27 & 18 & 4240 \\
Epididymitis & 7 & 33 & $4-72$ \\
Unilateral scrotal oedema & 2 & 9 & $6-12$ \\
Infected orchidopexy & 1 & 24 & \\
Hydrocele & 1 & 4 & \\
Undescended testis & 1 & 10 & $3-24$ \\
No abnormality detected & 7 & 32 & $3-240$ \\
All & 83 & & \\
\hline
\end{tabular}

Exploratory surgery was performed in 75 cases; $2 \%$ ioys had torsion of the testis and 15 of these required orchidectomy. Fifty eight patients were referred by general practitioners, 55 of them without delay. One boy who had had symptoms for over 24 hours was referred after a further 24 hours and had a gangrenous testis. All 25 patients who went to the casualty department were immediately referred for surgery. There was no appreciable difference in the duration of symptoms between patients who were referred by general practitioners and those who attended the casualty department. No testis was saved in which torsion had been present for more than 18 hours. The principal delay in diagnosis was attributable to the patient or his parents; although some sought immediate medical attention, most waited for a day or more (table).

All Saints' Hospital, Chatham, Kent ME4 5NG

S BENNETT, MRCP, registrar in paediatrics

M S NICHOLSON, MRCP, senior registrar in paediatrics

T M LITTLE, FRCP, consultant paediatrician

Correspondence to: Dr Little.

\section{Discussion}

Torsion of the testis carries a poor prognosis; in this series 55\% were lost, in others the loss has been as high as $80 \%$.' Surgeons have blamed general practitioners. and casualty officers for the poor results and editorials with such pejorative titles as "Castration by neglect" and "Torsion-continuing misdiagnosis" have appeared in leading journals. ${ }^{23}$ This year both defence societies drew attention to the medicolegal consequences of delays in diagnosis and urged doctors to be more aware of the condition. ${ }^{45}$

The results of this survey show that such sweeping criticisms are unjustified; all the hospital doctors and the great majority of general practitioners were quick to consider the diagnosis of torsion and to initiate the correct treatment. Delay in seeking medical advice because of ignorance of the sinister implication of acute testicular pain is the main reason for the poor results.

By extrapolation from our figures it appears that in the United Kingdom about 400 boys lose a testis through torsion every year. Greater public awareness of the condition is the only way to reduce this figure; increased medical efforts after late presentation will achieve little. Instead of criticising our colleagues we should try to devise methods of educating potential patients and their parents.

We thank D I Beeby, P L Girolami, R W Hoile, and P J Jennings for permission to study the patients under their care. We also thank Mrs T K Redknap for secretarial help.

\section{References}

1 Chapman RH, Walton AJ. Torsion of the testis and its appendages. BrMed f 1972;i:164-6.

2 Anonymous. Castration by neglect [Editorial]. $\mathrm{Br}$ Med f 1972;i: 128.

3 Anonymous. Torsion-continuing misdiagnosis [Editorial]. Lancet 1981;ii:76.

4 Jones HO. Leave no stone unturned. Fournal of the Medical Defence Union 1986;2:21.

5 The Medical Protection Society. Annual Report 1986;94:37-8.

(Accepted 3 February 1987)

\section{What is the latest thinking in malarial prophylaxis and treatment?}

It is usually better in areas where chloroquine resistance makes prophylaxis difficult to accept a less than $100 \%$ efficient prophylactic regimen than to put the patient at serious risk of poisoning from the antimalarials. Prophylaxis for the Middle East may be achieved with either tablets of proguanil hydrochloride $100 \mathrm{mg}$ (Paludrine), two tablets once a day, or tablets of chloroquine sulphate $200 \mathrm{mg}$, two tablets once a week, or tablets of chloroquine phosphate $250 \mathrm{mg}$, two tablets once a week. Both chloroquine preparations contain the same amount $(150 \mathrm{mg})$ of chloroquine base per tablet. For other parts of the world, a combination of proguanil, two tablets once a day, and chloroquine, two tablets once a week, is recommended. Where there is a high risk of chloroquine resistant malaria the combination of chloroquine, two tablets once a week, and pyrimethamine (Maloprim), one tablet once a week, gives a reasonably satisfactory degree of protection. All the same, breakthrough may occur even on this regimen and patients should be warned of it. Pyrimethamine, even at this dosage, has occasionally caused agranulocytosis, so obviously this combination should be recommended only when it is essential. Prophylaxis should always start at least a week before entering a malarious area and continue for four weeks after leaving. Treatment of malarial attacks is too long to be dealt with here but I cannot think of any circumstances in which treatment of the malaria would do more harm than the disease itself. A useful recent review "Severe and complicated malaria" appeared in the Transactions of the Royal Society of Tropical Medicine and Hygiene, 1986;80(suppl):1-50.—DION R BELL, reader in tropical medicine, Liverpool. 